\title{
Domestic Production Process of Early Korean Broadcast CG Equipment
}

\author{
So-Mi Nah ${ }^{1 *}$
}

\begin{abstract}
The development process of domestic CG (Computer Graphics) needs to be studied by classifying the technical part and the design part. This paper analyzes how early domestic broadcast equipment evolved and focused on what went through the development process. Domestic broadcasting companies have introduced and used overseas equipment and have begun to develop their own technology. The development process of the early domestic production technology of broadcasting stations was classified into Character Generator, On-line Real-Time Graphic and Sport Coder. It was found that the orientation of broadcasting technology was conclusively focused on visualization, with sociocultural factors acting along with the evolution of hardware and software. This research is meaningful in reorganizing the history of the development process of domestic CG technology in the early days through previous research (primary verification), newspaper articles and news coverage (secondary verification). This paper looks at what is missing by regaining the past of CG, and argues that with the advent of new technologies today, we must develop through appropriate division of roles and collaboration between engineers and designers.
\end{abstract}

Key Words: Computer Graphics, Character Generator, On-line Real-Time Graphic, Sport Coder.

\section{INTRODUCTION}

CG (Computer Graphics) technology has made many contributions to the visualization of human imagination. $\mathrm{CG}$, which has become more and more realized only by imagination and has satisfied the curiosity of the viewer, has improved its technical and expressive power as the times have changed. Now, when it became ambiguous even to separate the real world and the virtual world, it was sealed. The real change was brought about by the introduction of synthetic images such as interactive 3D computer graphics and computer animation. Through CG technology, time and space have been expanded infinitely. The audience was able to roam the simulated $3 \mathrm{D}$ space in real time. You can now see moments that you cannot perceive with your eyes. This is an experience not possible with a welcome painting [2]. In the 20th century, new technologies in reproduction and simulation were rapidly replaced, creating a constant parallax between our experience and understanding of the effects of the technology.

As viewers' expectations continue to rise, so does the pressure on $\mathrm{CG}$ designers who have to create new images, and the reliance on cutting-edge technology to find new images. It doesn't make sense to try new changes just for simple changes. There must be good reason to abandon the existing method and adopt the new method. In order to adopt new technologies and methods, we must focus on "how can we get new things", such as expanding the range of imagination through new methods. The media occupies the technology, form, and social meaning of other media and competes with or modifies them in the name of reality. It should be possible to claim that the device is better in order to gain reality and authenticity in any way. Their claim would also include redefining reality and authenticity to suit the new device. Only then will it become clear that the device is a medium. The use of the word image has more meaning than the meaning of psychological imaging that is universally inherent in one community. The image is comprehensively associated with the interests of the subject who produces and conveys it, the subject who accepts it and is subordinate to it, and the function of the social communication medium [4].

Domestic CG can be seen to have started in the 1980s. Although it departed a little later than overseas, it is now world-class competitive and is leading the design of the future in new technology areas such as virtual reality and

Manuscript received December 06, 2021; Revised December 19, 2021; Accepted December 23, 2021. (ID No. JMIS-21M-12-045) Corresponding Author (*): So-Mi Nah, 24 Beomil-ro 579Beon-gil Gangneung-si Gangwon-do, Rep. of Korea, +821038904204, nahsomi@cku.ac.kr.

${ }^{1}$ Departmen of CG-Design, Catholic KwanDong University, Gangneung-si Gangwon-do, Rep. of Korea, nahsomi@cku.ac.kr 
augmented reality. Currently, despite the fact that the status of domestic CG is at the world level, there is no historical study of domestic CG. Domestic CG started systematically at broadcasting stations. Therefore, this research has the following research scope, significance, and purpose:

1) It is important to historically rearrange the various viewpoints of the primary verification (previous research) of the development process of the first stage of domestic broadcasting $\mathrm{CG}$ technology through the secondary verification (newspaper and news coverage).

2) Looking back on the development goals and directions of early CG through the process of domestic production of broadcasting CG technology.

3) By looking directly at the limits of expressiveness of early CG technology, we will understand the past Korean $\mathrm{CG}$ and discuss the importance of collaboration between current engineers and designers.

Historical studies look back on the traces of the past we have lived in from a media perspective. We hope that this paper will help you to face the present and seek future directions through your understanding of domestic CG.

\section{EARLY KOREAN BROADCAST CG EQUIPMENT}

\subsection{Character Generator Development}

It can be said that CG (Computer Graphics) in Korean broadcasting started with the advent of CG (Character Generator). Therefore, there was a chaos between computer graphics and Character Generator, and $\mathrm{CG}$ began to develop earlier in the field of technology than in the field of design. In fact, KBS's "Computer Graphics Room", founded in the 1980s, was an area of technology. The birth of the Character Generator used in TV broadcasting was developed before the CG equipment for TV broadcasting for use on video screens. Goo-Eon Jeong, then Head of Operations for KBS Computer Graphics Room, said the reason was that the process of making with Character Generator was easier than with graphic equipment that draws video screens.

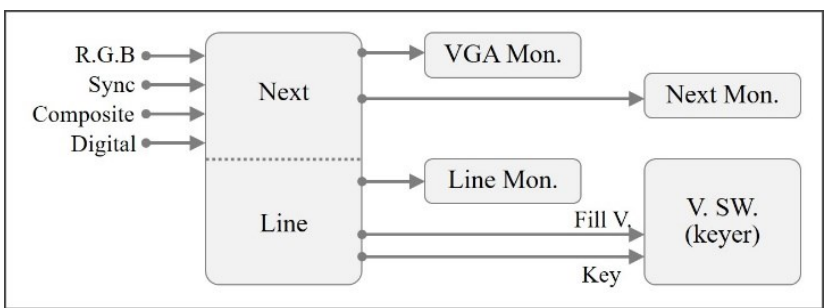

Fig. 1. Character Generator Configuration [1].

Character Generator is divided into "pre-production" and "live broadcasting" and used. The "pre-production"
Character Generator uses only one graphic board to use both production and delivery. Therefore, when it comes during the transmission of the program, it immediately moves to the correction stage from the confirmation of the omission, and it is not easy to use and is used as "preproduction". On the other hand, the "live broadcasting" Character Generator has two graphic boards, so you can use production and transmission properly.

Domestic engineers have begun to create Character Generators for the following reasons. If you make a "Remote Control Panel" separately and use it, you can easily call up the completed file and send it out easily. The Character Generator is configured as shown in Fig. 1. You can easily find and correct typographical errors and omissions in "Next Preview" and send or create programs. The "live broadcasting" Character Generator prepares the video on two graphics boards. The graphic board is divided into "Next Preview" and "Line Program". "Next Preview" is a part that receives an external synchronization signal or video input, or produces characters, and shows the video that is waiting at the time of transmission. The "Line Program" can be immediately combined with other backgrounds and sent [1].

Workers who recalled that time said that they were called "pip-pip-pip-po" because they could make a "pip-pip-pip" sound by themselves if they entered numbers on the dial of the Character Generator. There is a separate occupational part to type in the Character Generator, and the designers worked by drawing letters on paper separately. The system shown in Fig. 2 is a method of drawing characters, shooting them with a camera, and encoding them into a graphic device. In this way, designers play a major role in program titles in the 1980s, subtitle processing and graphics for Korean TV news, weather forecasts, etc., which is called "the beginning of CG".

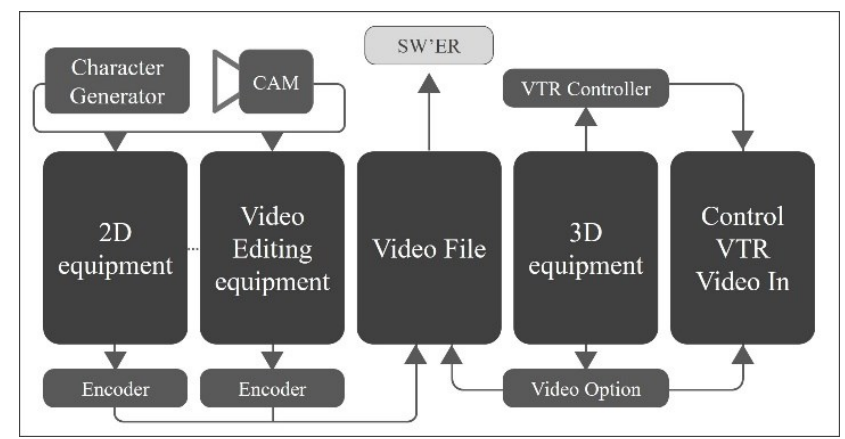

Fig. 2. Broadcaster's Report Production CG System [6].

Fig. 2 is a system that produces and sends CG using the 1980s Character Generator and 2D and 3D devices. Characters taken by the camera are combined with the video in the concept of layers with editing equipment or $2 \mathrm{D}$ equipment, and sent as a video file through output 
equipment. The CG image generated using the $3 \mathrm{D}$ device is output to a file or VTR device and sent as a video file. Proceed to produce and match video files in the "general editing room". Character Generator was mainly used to guide broadcast order, breaking news, disasters, notices, spots, step announcements, etc. [14]. KBS and MBC used the Character Generator (CG-800) introduced in 1981, but it was impossible for the character generators in developed countries to express "Korean fonts" in terms of design. Fortunately, since 1983, we have been able to develop various types of Character Generators in South Korea due to the influence of PCs (Personal Computers). SBS, which opened in 1991, also introduced the Character Generator, which was commercialized due to lack of time to develop by itself at the time of opening, and since using it, it has been developed according to the demands of the current business. With the development of Character Generator with domestic technology, it became the beginning of domestic fonts. While broadcast programs are being produced in the flood of exterior equipment, Korean small and medium-sized enterprises have developed the "Character Generator that shows characters on TV screens" and have begun to use it mostly within Korean broadcasting stations. Gung-Deok Nam [25] Explained that this period was "the expulsion of exterior equipment in the Character Generator market" due to the domestic production of broadcasting-related equipment such as Character Generator and computer graphic switchers.

Table. 1, partially referred to the contents excerpted from the graphics technology [6] in Korean broadcasting by the author and the hardware and usage of the Character Generator described in the previous research [3, 14]. The parts with different notations were confirmed through the news coverage at that time, and the "year of introduction and development of Character Generator by broadcasting company" was reorganized.

In Table 1, it is indicated as follows.

D* (Development), $\mathrm{H}^{*}$ (Have: overseas purchase).

Table 1. Character Generators for Korean Broadcasters.

\begin{tabular}{|c|c|c|c|}
\hline & KBS & $\mathrm{MBC}$ & SBS \\
\hline 1983 & $\begin{array}{l}\text { Character } \\
\text { GeneratorD* } \\
\text { - With Z80: video } \\
\text { memory control } \\
\text { system } \\
\text { - Fontporting }\end{array}$ & $\begin{array}{l}\text { Supercom D* } \\
\text { - Subtitle } \\
\text { processing } \\
\text { - Roll, Crawl } \\
\text { - Still File storage } \\
\text { (450 sheets) }\end{array}$ & \\
\hline 1984 & $\begin{array}{l}\text { Datavix D* } \\
\text { - NEC, PD7220 } \\
\text { (CRT Controller } \\
\text { Chip) } \\
\text { - H/W }\end{array}$ & & \\
\hline
\end{tabular}

\begin{tabular}{|c|c|c|c|}
\hline & $\begin{array}{l}\text { - Computer } \\
\text { Connection }\end{array}$ & & \\
\hline 1985 & & $\begin{array}{l}\text { Solger } 2000 D^{*} \\
\text { - } 15.7 \text { million } \\
\text { colors } \\
\text { - Color } \\
\text { Animation } \\
\text { (Cycling), Mirror } \\
\text { Effect, etc. }\end{array}$ & \\
\hline 1986 & $\begin{array}{l}\text { Vidimaster 16Bit } \\
\text { D* } \\
\text { • IBM/XT,No-9 } \\
\text { Graphics Board } \\
\text { - 256 colors ( } 8 \\
\text { bits/pixel) } \\
\end{array}$ & Grafont Solger D* & \\
\hline 1987 & $\begin{array}{l}\text { PRISMD* } \\
\text { - IBM/AT (386PC } \\
\text { system), Targa+32 } \\
\text { Board } \\
3200 \text { colors }(15+1 \\
\text { bits/pixel) font } \\
\text { ROM }\end{array}$ & & \\
\hline 1988 & & $\begin{array}{l}\text { ParagonD* } \\
\text { - Separate Bit- } \\
\text { SliceCPU, Raster- } \\
\text { Engine for real } \\
\text { time }\end{array}$ & \\
\hline 1989 & & $\begin{array}{l}\text { CANVASD* } \\
\text { - Graphic } \\
\text { - Standard } \\
\text { character notation } \\
\text { - Video input } \\
\text { - On-line }\end{array}$ & \\
\hline 1991 & $\begin{array}{l}\text { PRISMPlus D* } \\
\text { - 486PC basic } \\
\text { system } \\
\text { - Targa+64Board }\end{array}$ & & $\begin{array}{l}\text { F-Scan H* } \\
\text { - PS/386 Targa } \\
\text { Board installed }\end{array}$ \\
\hline 1993 & $\begin{array}{l}\text { PRISMPro D* } \\
\text { - Editor Program } \\
\text { development and } \\
\text { transplantation }\end{array}$ & $\begin{array}{l}\text { Fantasia } D^{*} \\
\text { - PC slot } \\
\text { mounting board } \\
\text { type }\end{array}$ & \\
\hline \multirow[b]{2}{*}{1994} & & \multirow[b]{2}{*}{$\begin{array}{l}\text { Spotia } \mathrm{D}^{*} \\
\text { - Shape generator }\end{array}$} & $\begin{array}{l}\text { Power-CGH* } \\
\text { - PS/486 Targa } \\
\text { Board, Power-CG } \\
\text { - Font outline } \\
\text { improvement }\end{array}$ \\
\hline & & & $\begin{array}{l}\text { Portable Character } \\
\text { GeneratorD* } \\
\text { - Use of narrow } \\
\text { space } \\
\text { - NotebookPC } \\
\text { Character } \\
\text { Generation }\end{array}$ \\
\hline 1995 & $\begin{array}{l}\text { PRISM GEMD* } \\
\bullet \text { HD production }\end{array}$ & & $\begin{array}{l}\text { CAPS D* } \\
\text { - PS/486 Targa- } \\
\text { 32 Board }\end{array}$ \\
\hline
\end{tabular}


- Texttype Soft

edge

\section{SDDaVinci D*}

In the title of Table 1, KBS (KBS Institute of Technology), MBC (MBC Institute of Technology), and SBS (Technology Research Department) are included.

The duplicated contents of the broadcasting stations in Table. 1 are supplemented and described as follows. In 1986, the KBS and MBC Character Generators were developed for "international signal production of Seoul Asian games". It contains a part for writing and saving national flags, pictograms, Korean fonts, English fonts, symbols, etc. The KBS (1987) and MBC (1988) character generators were developed for "international signal production of the Seoul Olympic games." "PRISM" was demonstrated in advance at the "Presidential Election" in 1987. "Paragon" was developed to enable high-speed processing of characters. KBS in 1991 developed "PRISM Plus" for "city street assembly election ballot counting". Subsequently, in 1995, it was developed as "PRISM GEM" and "for local election ballot counting broadcasting". In 1994, MBC developed "Spotia" for subtitle processing during sports broadcasts. Used in basketball, Hiroshima Asian games, World Cup soccer, national battles, and in conjunction with marathon rangefinders. MBC developed "Solger 2000" (1985) and "CANVAS" (1989), which were used for title and logo production.

In Table 1, the development process appears by applying the technique of gradually increasing the number of colors in the development direction of the character generator and smoothing the edge of the character form. It can be seen that the Character Generator was developed mainly for sporting events and election broadcasting.

The author states that previous studies have the following disagreements: KBS used to rely only on the scanner chain, and introduced "Datavix" in 1982 to complement it. Until 1987, it was possible to produce 16 colors (4 bits / pixel) using an MSX microcomputer as an input terminal. Utilizes a production system with excellent performance [14]. In the development process of Character Generator by KBS year, KBS news agency introduced Shaken's new "SPICAAPKT" in 1981, and KBS technical agency introduced KOWA's CG (Character Generator) -800 (Character Generator for the first 8 Bit On-Line). Developed "XiphiasAeds 11" (TV's first pen type Stylus and Keyboard adopted) in 1984, and KBS Technical Research Institute character generator "Datavix" in 1985. Developed by KBS Technical Research Institute Vidimaster 16Bit in 1986, he was in charge of "1986 Seoul Asia game" characters and graphics [3]. Subsequently, in 1988, Shaken's "Telomaiyer-T" (KBS news office adopted a roller print method instead of photographic paper) was introduced. KBS Technical Research Institute developed "Prism" in preparation for the "1988 Seoul Olympics". In the 1990s, the phototypesetting machine disappeared, and the use of Character Generator expanded. In 1993, he developed "Prism Pro ACE" (Character Generator device with upgraded Prism functions). In 1998, "DaVinci" was developed for local election ballot counting broadcasting (using Window standard TrueType font at KBS Technical Research Institute) [3].

Such technology shows a discrepancy in the development year between previous papers, magazines, and news reports. In this paper, Table 1 . refers to existing academic journals, but was created based on the content of news reports and interviews at that time in various notations.

The modernized "F-Scan" was introduced from the "Seoul Asian Games" held in 1986, and was sent directly from the broadcasting station. In 1987, KBS Technical Research Institute developed "PRISM" (Professional Real Image Sketch Machine) for such character graphic equipment, and it was used for the 1988 "Seoul Olympic Games" and began to develop in earnest [18]. It was replaced by PRISM Plus in 1991. In 1995, PRISM was equipped with a GEM Board that can give effects to character data, and "PRISM GEM" (GEM: Graphic Effect Machine) was developed to improve the output effect while utilizing large-scale program production. Since 2001, "DaVinci" has been developed and used for each program. "PRISM GEM" is a graphic character effector based on Character Generator technology and digital video effect technology, and executes multiple graphic elements including characters in real time. Based on a PC system that uses a Pentium CPU, it uses 32MB of main memory and $1 \mathrm{~GB}$ of hard disk. It is a PC-type equipment equipped with a graphic board and a specially made effect board, and it is small and economical. You can edit various characters and graphics, and give various path movement effects such as curves and spirals, as well as effects such as position conversion, size conversion, rotation, tilt, bending, spreading, clipping, scrolling, and blinking [10].

In summary, subtitles have been an indispensable part of video program production since the opening of KBS, and in 1981, while introducing the Shaken (SPICA-APKT) and Kowa (CG-800) systems from Japan, subtitle design using a full-scale Character Generator I started. Then, after the announcement of IBM / XT, devices using personal computers were developed. In 1984, NEC's PD7220 was used to develop and use "Datavix". We developed the "Vidimaster" (16bit) as a Character Generator for international signal production of the "Asian Games" held in Seoul in 1986, and saved and used Pictograms used for 
the broadcast broadcasting of the "Asian Games". "Vidimaster" was the beginning of a technological development effort for the internationalization of domestic broadcast subtitles, and has since taken steps to develop "PRISM" and "PRISM Pro" (1993) for the 1988 "Olympic Games". The expansion of computer-based subtitle design was the catalyst for the introduction of designer jobs as technical jobs.

Hyun-joo Cho, who produced the subtitles for the "Seoul Asian Games" broadcast, said that he drew more than 2,000 characters one by one and pasted them in a cell format because there was no Korean font at that time. Whereas some designers developed fonts and pictograms, the need for designers arose with the development of Character Generator. The advanced broadcasting graphic equipment had a lot of various typefaces and image contents. This required the ability of the designer because it required a sense of utilizing the image and typeface that matched the right place for loading.

But unfortunately, in the broadcasting business, in addition to character generators and 2D graphics tools, all equipment was imported from the United States, Canada, the United Kingdom, Japan, etc. and operated, and it is still the case.

\subsection{On-line Real-Time Graphic}

On-line Real-Time Graphic means a function to graphically display unpredictable data in real time on a graphical screen.

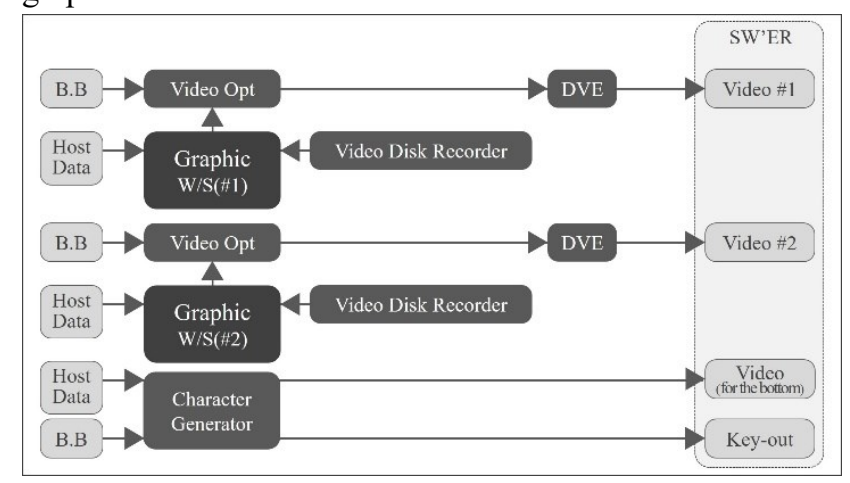

Fig. 3. Graphic System for Election Counting Broadcast [6].

A typical example of such a function is "election ballot counting broadcast". In this case, after the aggregated data is processed by "Host Computer", the vote counting data of a specific candidate must be displayed on the screen in real time. Therefore, it includes both "On-line" and "RealTime" functions. Election ballot counting is a broadcast program that distributes various data related to elections, especially ballot counting data, to viewers in real time. When classified in terms of technology, it is a form of information broadcasting. As shown in Fig. 3, there are videos 1 and 2 output from "Host Computer" using a graphic board. There is a video that is immediately configured for the lower row by using the character generator to automatically operate the keys on "Host Computer". It was in 1985 that the "General Election of Parliamentarians" introduced this concept into the election counting broadcast. At that time, the process of writing on a chart, taking it with a camera, and then sending it out was simply displaying the vote data as a Character Generator, but after that, the character generator and various graphic devices were used as the main computer for data aggregation and signals. By interacting with each other, the screen will be created and the animation will become more and more gorgeous. Most of the CG of domestic broadcasting companies in the 1980s was reported. As mentioned above, from the "12th House of Representatives Election (1985)", the election counting was started using a computer in South Korea [7], but MBC started "EDDS" (Election Data Display System) was developed and constructed and used for election broadcasting [8], [24].

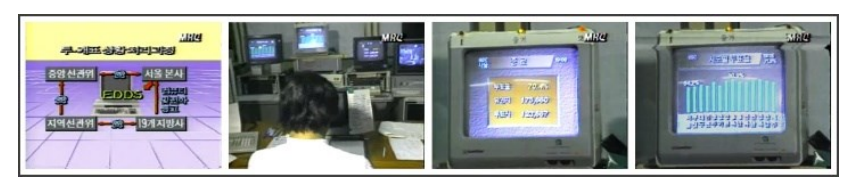

Fig. 4. Election Counting Broadcast by Computer [24].

MBC News [24] has developed "EDDS", that is, a computer system for election broadcasting since the 12 th general election in 1985, and used it for referendums and presidential elections, and developed "EDDS" at that time. The content about the system accomplished the main. Seen as "computer-based election voting and ballot counting," it shows that it focuses on $\mathrm{CG}$ functions rather than $\mathrm{CG}$ images.

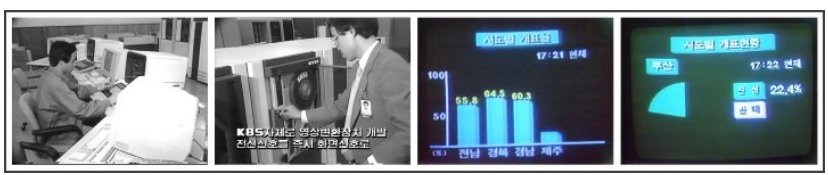

Fig. 5. Computer Broadcasting System [17].

The computer signal television video converter was developed for the first time in the history of ballot counting in the "6th Referendum (1987)" Fig. 5 [17]. This is said to help viewers understand by changing what was expressed only in numbers in a computer information processing system that can convert calculated signals into screen signals into various charts and visual materials. As you can see from the content of this news report, CG was graphic by machines at that time. This indicates that the numerical chart and the movement of the center of the text were first embodied as an image by the image converter.

In the case of KBS, the above various Character 
Generators were used by connecting to the "Host computer". In the 1990s, it was used for animation using SGI's 310 / VGX workstation and Onyx workstation. He also developed and used a technology to synthesize a graphic screen and a live-action screen using a Chroma key interlocking camera. In the case of $\mathrm{MBC}$, the names of the graphic systems for election ballot counting were named "EDDS", "MAGIC I", "MAGIC II", etc. Initially, I used a character generator that I developed independently by connecting it to the main computer. After that, I used the Iris-Vision Board developed for PC by SGI for animation. Like KBS, I used it for animation using SGI's Onyx workstation. Initially, SBS also used a Character Generator connected to a Host computer like KBS and MBC. I used VISTA Board etc. for animation. The name of the system was "VIPON" (Voting Information Processing On-Line Network), which was named "VIPON I", "VIPON II", and "VIPON III", and was also used for animation using SGI's Onyx workstation [6].

According to an article in 1992, as a result of the voting of the "14th presidential election", advanced equipment was mobilized for broadcasting. KBS is an automatic response system named "ARS", which is a game of breaking news and analysis. MBC connected the main computer system "EDDS" developed in-house to a value-added communication network such as VAN / LAN, and fought a total war with a system called "MAGIC" (MBC's Advanced Generator for Information \& Communication). SBS explained that in order to overcome the weaknesses of metropolitan broadcasting, the "VIPON II" system, which connects the pioneer office and the head office to the micro transmission network, was fully operated to compete for advanced equipment [26].

The connection between "Character Generator" and "Online Real-Time Graphic" will develop into a "virtual studio". Broadcasting companies began to develop virtual studios starting from "election broadcasting", but Table 2 . summarizes $\mathrm{CG}$ technology and virtual studios in the election broadcasting of each broadcasting company with reference to news reports and newspaper articles at that time.

Table 2 is the start time of the virtual studio until the 2000 s, and is a table that concatenates the equipment used based on the "election Year" instead of the "development and introduction Year".

In Table 2, it is indicated as follows.

$\mathrm{P}^{*}$ (presidential election), $\mathrm{G}^{*}$ (general election), $\mathrm{L}^{*}$ (local elections)

The virtual studio, named 3D, was built with the development of 2D-based Chroma key technology. The evolution of virtual studios can be seen only by understanding the previous CG technology, rather than describing it from SBS (1996), which began to use it in earnest. SBS's virtual studio is evaluated to have brought about "innovation of TV broadcasting technology" as well as election broadcasting by utilizing "The world's First virtual studio" as "live" for "election broadcasting" in the 1996 general election. KBS already used the Chroma studio in the "local election ballot counting broadcast" through the "SMOKEY" (Synchronized Motion Chroma Keyer) system [5], [22], [27], [28] in 1995.

Table 2. Korean Broadcasting company virtual studio.

\begin{tabular}{|c|c|c|c|c|}
\hline & & KBS & MBC & SBS \\
\hline 1985 & $\mathrm{G}^{*}$ & & EDDS System & \\
\hline 1987 & $\mathrm{P}^{*}$ & PRISM & EDDS System & \\
\hline 1988 & $\mathrm{G}^{*}$ & PRISM & EDDS System & \\
\hline 1992 & $\mathrm{G}^{*}$ & PRISMPlus & EDDS System & \\
\hline 1992 & $\mathrm{P}^{*}$ & $\begin{array}{l}\text { PRISMPlus } \\
\text { ARS }\end{array}$ & MAGIC System & \\
\hline 1995 & $\mathrm{~L}^{*}$ & $\begin{array}{l}\text { PRISMGEM } \\
\text { SMOKEYSystem }\end{array}$ & MAGICII & \\
\hline 1996 & $\mathrm{G}^{*}$ & SMOKEYII & MAGIC III & Virtual Studio \\
\hline 1997 & $\mathrm{P}^{*}$ & Dream Studio & $\begin{array}{l}\text { MAGICIV } \\
\text { Imagebox }\end{array}$ & Virtual Studio \\
\hline 1998 & $\mathrm{~L}^{*}$ & DreamStudio & Image box & Virtual Studio \\
\hline
\end{tabular}

The virtual studio, named 3D, was built with the development of 2D-based Chroma key technology. The evolution of virtual studios can be seen only by understanding the previous CG technology, rather than describing it from SBS (1996), which began to use it in earnest. SBS's virtual studio is evaluated to have brought about "innovation of TV broadcasting technology" as well as election broadcasting by utilizing "The world's First virtual studio" as "live" for "election broadcasting" in the 1996 general election. KBS already used the Chroma studio in the "local election ballot counting broadcast" through the "SMOKEY" (Synchronized Motion Chroma Keyer) system [5], [22], [27]-[28] in 1995. There is also the perspective of seeing KBS's "SMOKEY" system for the first time in a virtual studio. KBS developed a smoky system with its own technology in 1995 and used it for the local government election broadcast that year. This is the first case of using a virtual studio in the history of Korean broadcasting [11].

SBS's "Virtual Studio" used Israeli RT-SET as a rental broadcast, KBS's "Dream Studio" supplemented and utilized Synthevision, which was transferred from NHK in Japan, and MBC's "Image box" was jointly developed and used with KIST.

\subsection{Sport Coder}


When changing various graphic data to a graphic screen, sports broadcasts, university entrance exam broadcasts, disaster fundraising broadcasts, etc. are applicable in addition to election broadcasts. In the case of sports, the score cannot predict the interim or final result of the match, so you should be able to view the score and player data with a simple operation of the relay agent. Broadcasters call such equipment a "Sport Coder." Sport Coder is a system that links various recorded data with state-of-the-art graphic equipment and appropriately provides viewers with highlevel graphics and subtitles in real time. In Sport Coder, CG personnel can be classified into coder operation personnel in charge of recorded data, character generation personnel in charge of subtitles, and graphic personnel [16].

The reason why sports coders are important in graphic design is that providing key records that are more detailed than other broadcasters enhances the expertise and quality of relay broadcasting and has a positive impact on the construction of Station Image [16]. Along with this, the 1995 sensor was used to express the speed and wind direction strength of the athletes during the race on a graphic screen [20].

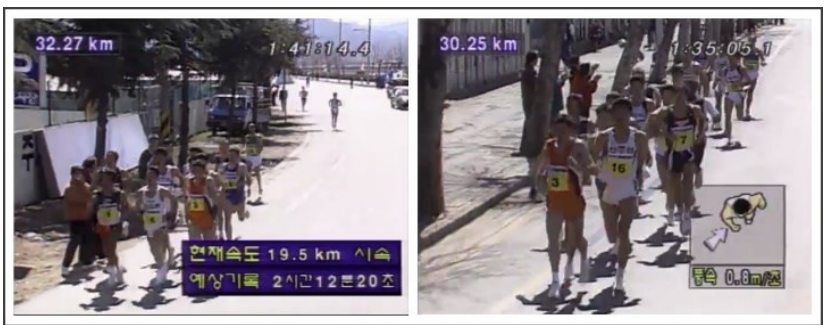

Fig. 6. KBS Dong-A International Marathon (1995) [19], [20].

KBS News [19] reports on the graphic screen of the "Dong-A International Marathon Tournament" at that time Fig. 6, and has interesting graphics and advanced equipment to predict the expected time of the players' goals. He said that he showed a one-dimensionally higher marathon broadcast by mobilizing technology.

Such graphics are represented by data input and belong to elements such as points, lines, faces, icons and pictograms. Nowadays, the expression of images is developing because of interesting elements.

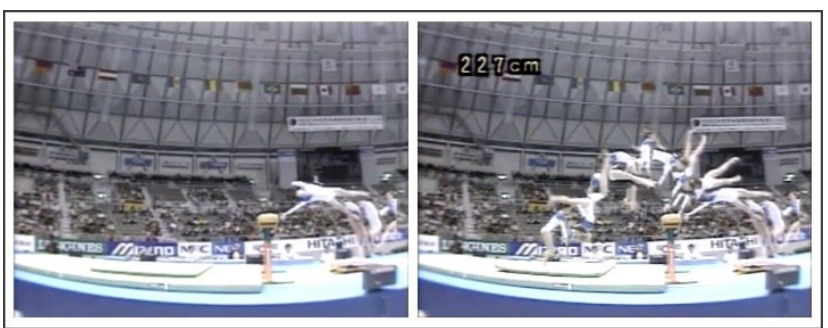

Fig. 7. Multi-Motion Video Technique [21].
KBS News [21] said that a new video technique was developed that allows you to see all the momentary movements of athletes on one screen in gymnastics competition, and introduced it as "multi-motion video technique" Fig. 7. Sang-Gil Lee (Director of KBS Technology Research Center), who developed this technique, changed the form of the athlete by displaying the continuous movements performed by the gymnast on one screen, unlike the "slow motion" so far. We interviewed that we tried to make it possible for viewers to see at a glance whether it would change. KBS [21] reported that this video processing technique can be applied to other fastmoving games, and that multi-motion broadcast broadcasting is expected to expand in the future.

"Slow motion" production technology was introduced for the first time at the "1968 Mexico City Olympics". However, at this time, the screen seemed to simply play slowly for the viewer to see [16]. At the "1988 Seoul Olympic Games", a nice slow motion was certainly performed with the isolated camera [15].

Since the end of the 1990s, such multi-slow motion techniques have often been used to express spectacular images in movies and dramas. It also triggered the development from a single point in time to a point of 360degree rotation.

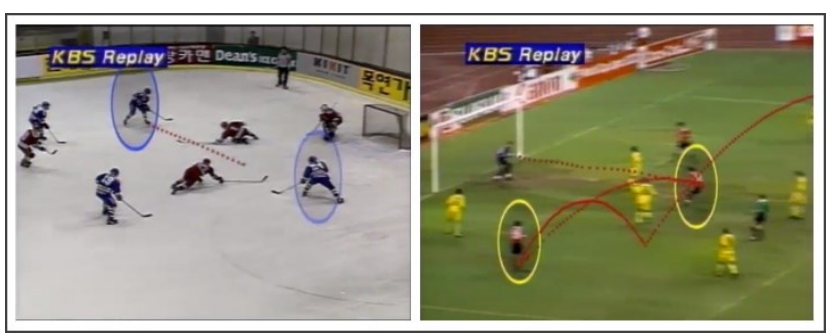

Fig. 8. Digital Replay 2000 [23].

In 1996, we introduced the state-of-the-art sports broadcasting facility "Digital Replay 2000". Traditional sports broadcasts have all been about replaying and showing slow screens again. "Digital Display 2000" allows you to see the content of the competition more visually using computer graphics, analyzes the movements of athletes and the direction of travel of speed, and expands important moments to one side of the screen at the same time. It has various functions such as showing. It is the first model that can be enjoyed not only by watching the game but also by detailed analysis [23]. In this way, through the news, the development and utilization of advanced technology at that time is meaningful for understanding the era. In 2009, it was necessary to convert subtitles displayed in English American units such as "MPH (miles per hour)" to " $\mathrm{km} / \mathrm{h}$ " according to the domestic situation in overseas sports broadcast production such as major league baseball 
broadcast [12]. KBS has developed a sports subtitle recognition system for this purpose. This system senses that the subtitle is displayed from the change of the subtitle area displayed on the relay screen, and recognizes the numerical information.

At the time of converting this into "SI" units that suit the domestic situation, "neural networks" -based methods such as "multi-layer perceptron" are generally used for character and number recognition [9], [13].

This method requires a neural network training process using similar data before utilizing the recognition system, and the shape (font, size, color, etc.) that is completely different from the data used for training is required. It can be dealt with when subtitles are used. Seeing that it has the drawback of not being present [12], the fact that the fonts specified in such a live broadcasting system were used before that means that $\mathrm{CG}$ is the role of technology in this part. It turns out that it was not the role of the designer.

\section{CONCLUSION}

This paper chronologically describes the localization process of early broadcast CG technology. The content of the study was to identify changes in the past system, and to explore the direction of technological advancement through analysis of use cases in broadcasting.

1) This thesis is meaningful in classifying and rearranging the development process of early broadcast $\mathrm{CG}$ technology as an archive due to the absence of existing CG historical research. The process of localization of broadcasting technology in the early days was established by the social, cultural, and industrial demands of the time, and industrial, technical, and aesthetic conditions were inherent.

2) This study was classified into three categories: Character Generator, On-line Real-Time Graphic, and Sport Coder.

It was found that the purpose of the Character Generator development was technologically advanced to express graphic factors in a more readable way, based on sports events and election broadcasts. Character Generators were developed sequentially, along with computer functions, to diversify color, animation, effects, and image expression, and to naturally express images. On-line Real-Time Graphic was mainly used in election broadcasting, and it has developed in the direction of showing colorful graphic elements that can catch the eye for immersion in broadcasting. Sports coders have shown the direction of development from records to predictive systems. The "Multi-Motion Video Technique" and "Digital Replay 2000" technology developed by Sports Coder were later used to give dramatic effects in dramas and films.
Technological development is established by accommodating social psychology and tastes, and awareness of the times is already contained in it. With the recognition that broadcasting technology advances to solve aesthetic problems, these aesthetic problems are mostly related to realism.

3) The advancement of technology is the process of completing the realism myth that expands the frame. The various reactions appearing in the introduction of new technologies show that the process of establishing new technologies depends on the psychological system composed of viewing conventions. In this historical study, it was found that CG technology is achieved by the change patterns of "Invention", "Innovation" and "Diffusion". In addition, it was found that the process of technological change has been achieved through the cycles of "Differentiation", "Appropriation", and "New Differentiation" for the dominant technological form.

Therefore, this paper argues that whenever new media emerges, constant demands are exchanged between engineers and designers, and creation and development must be done through collaboration.

In Korea, engineers introduced and developed CG, but the current CG work is led by designers. The history of CG in developed countries was not only the level of utilization, but also the history of invention and development. In order to apply graphics to the first computer invented, it developed hardware and software and pioneered the market by constantly applying it to new fields. On the other hand, Korean CG workers imported the hardware equipment and software they invented, were educated on how to operate them, and had no choice but to follow their application methods. The broadcasting station's CG team was created by engineers for their jobs. As CG developed, there was a limit to image expression only with the technique of the technical team. As art majors began to be hired to express better images, designers were hired by the broadcasting $\mathrm{CG}$ team after the 2000 s.

Through the study of the history of broadcasting CG, I came to understand the past of Korea, where there was no choice but to compete with technology. This thesis dealt with the 1980s and 1990s, revealing the history of early broadcast CG. At that time, it was found that $\mathrm{CG}$ was mainly classified as a technical part and developed, and it was only after the 2000 s that CG came to be known that designers and engineers formed a team together. This is a differentiated record of the history of Korean broadcasting CG. Even now, whenever a new medium emerges, I feel that the viewpoints of engineers and designers are different, and they tend to stick to their respective fields. In the past, technology was the main focus, but now technology and design must always evolve through collaboration. I hope 
that the understanding of technology from the point of view of design and the understanding of design from the point of view of engineers will be broadened.

\section{REFERENCES}

[1] G. Jung, TV broadcasting system operation and production, Cheongmungak (Gyomunsa), 2012.

[2] Manovich. Lev, The Language of New Media. Cambridge: The MIT Press, 2001. As J. Seo, The language of new media. Seoul: Tree of Thoughts, 2004.

[3] S. Lee, Hangeul for broadcasting text messages delivered to TV, All about Hangeul Typography, Hangul Typography Magazine, Yun Design Lab, 2009.

[4] B. Choi, "Computer graphic image, ideology, technopia," cultural science, vol. 1, pp. 210-218, 1992.

[5] C. Choi, "Broadcast times are extended, and program development is sluggish," Korea Press Foundation, newspapers and broadcasts, vol. 12, pp. 19-23, 1996.

[6] G. Oh, "Graphic technology in Korean broadcasting," The Korean Society of Broad Engineers, vol. 1, no. 1, pp. 48-53, January 1996.

[7] I. Kim, "Media role sharing-broadcasting," Korea Press Foundation, newspapers and broadcasts, vol. 6, pp. 1821, 1995.

[8] J. Oh, "The general election ballots are counted by computer and broadcast on EDDS-MBC," Korea Press Foundation. newspapers and broadcasts, vol. 6, pp. 2426, 1988

[9] M. Egmont-Petersen, D. de ridder, and H. Handels, "Image processing with neural networks a review," Pattern Recognition, vol. 35, no. 10, pp. 2279-2301, 2002. https://doi.org/10.1016/S0031-3203(01)00178-9

[10] S. Park, K. Lee, G. Park, and B. Lee, "The Development of Real-time Character Effector: PRISM GEM," The Korean Institute of Broadcast and Media Engineers, pp. 107-112, 1996.

[11] J. Lee, S. Lee, and C. Kim, "A Study on the Domestic Program Using Virtual Studio Production," The Korea Institute of Information and Communication Engineering, pp. 339-342, Spring. 2010.

[12] J. Oh, "Development of a Video Caption Recognition System for Sport Event Broadcasting," The HCI Society of Korea, pp. 94-98, February. 2009.

[13] D. Chen, "Text Detection and Recognition in Images and Video Sequences," Ph. D. IDIAP, Switzerland, 2003.

[14] D. Jung, "Audience reaction to text graphic in broadcast video," Ph. D. HongIk University, Korea, 2008.

[15] J. Shin, "A study on the viewing behavior of Olympic relay broadcasting," M. S. thesis, ChungAng University,
Korea, 2012.

[16] S. Ha, "A study on the change in the production style of Korean TV sports broadcasts: focusing on professional baseball broadcasts," Ph. D. KonKuk University, Korea, 2014.

[17] KBS News, "People referendum on constitutional amendment, computer broadcasting system of ballot counting," October 27, 1987.

[18] KBS News, "The 13th Presidential Election Counting Broadcast Advanced System,” December 17, 1987.

[19] KBS News, "Would you like to break the world record?" March 18, 1995.

[20] KBS News, "KBS marathon broadcasting opens a new chapter," KBS News, March 19, 1995.

[21] KBS News, "Development of an imaging technique that can view instantaneous motion on one screen," October 11, 1995.

[22] KBS News, "Producing cutting-edge video for the 15th general election counting broadcast," April 10, 1996.

[23] KBS News, "KBS, the first state-of-the-art broadcasting through digital replay," May 8, 1996.

[24] MBC News, "The process of voting and counting broadcasting by computer," August 26, 1988.

[25] G. Nam, "Broadcasting equipment small and mediumsized companies develop 'eyes', Compix invests $30 \%$ of sales," Hankyung News, March 3, 1994. https://www.hankyung.com/news/article/1994030300871

[26] H. News, "Broadcasting the results of the three TV presidential elections Fierce competition for cuttingedge equipment," Hankyung News, December 18, 1992. https://www.hankyung.com/news/article/1992121802551

[27] J. Kim, "broadcasters, general election counting broadcast to be a high-tech battleground," Korea Economic Daily, April 9, 1996. https://www.hankyung.com/life/article/1996040901871

[28] M. Oh, "4.11 General Election Casting/Vote Counting Broadcasting, High-tech Equipment Competition," Maeil Business News, April 10, 1996. https://www.mk.co.kr/news/home/view/1996/04/17405/

\section{Author}

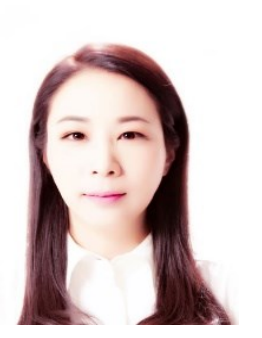

So-Mi Nah received a Bachelor of Arts in Multimedia Design from HongIk University in 2000. In 2007, he received a master's degree in Fine Arts from Honglk University's Department of Film Design. In 2011, she completed the doctoral program in the Department of Imaging at HongIk University. From 1999 to 2016, she did CG work in $\mathrm{CF}$, film, and broadcasting stations. The final position is 'CG Supervisor'. She created the first 'Department of CG Design' in Korea within the Catholic KwanDong University in 2016. 
From 2016 to the present, she has been serving as the head of department the 'Department of CG Design', Catholic KwanDong University.

She studies video design, CG, VFX, motion graphics and history. 